\title{
Power losses of 2 G HTS coils measured in external magnetic DC and ripple fields
}

\author{
Michal Chudy ${ }^{1,2}$, Yiran Chen ${ }^{1}$, Min Zhang ${ }^{1}$, Mehdi Baghdadi ${ }^{1}$, Jörg Lalk $^{2}$, Tinus Pretorius ${ }^{2}$, \\ Tim Coombs ${ }^{1}$ \\ ${ }^{1}$ Department of Engineering, University of Cambridge, 9 JJ Thomson Avenue, Cambridge CB3 0FA, UK \\ ${ }^{2}$ Graduate School of Technology Management, University of Pretoria, Pretoria, South Africa
}

\begin{abstract}
Power losses are an important phenomenon in $2^{\text {nd }}$ type superconductors. Precise evaluation of power losses in superconducting coils is crucial for the design of novel machines such as superconducting motors or generators. Although AC losses are relatively easy to measure with electrical methods, it is more difficult to measure power losses in the DC mode, induced by varying external magnetic fields, such as occur in a real operating environment. Especially the problematic one could be the direct-drive wind generator, where several elements introduce nonsynchronous disturbances to the magnetic fields. Modelling had been carried out by numerous authors ${ }^{1-4}$ in order to estimate the power losses in $2 \mathrm{G}$ HTS coils under various external DC or ripple fields; however experimental work in the area is less common due to the difficulty of conducting experiments and special equipment requirements. In this paper, power losses are experimentally measured by the calorimetric method.
\end{abstract}

\section{Introduction}

In recent years, HTS (High Temperature Superconductor) applications such as motors and generators have been the subject of a high level of interest. Among all the possible applications of HTS, applications in renewable energy have very strong potential. Recent 
developments in wind energy generators are strongly focused on direct drive wind turbines due to higher reliability; lower maintenance costs and lower noise profile. To remove the requirement for gearboxes, which are responsible for long periods of outages ${ }^{5}$, necessitates bigger and heavier direct drive generators. Since there are some weight and size limits for construction and operation of the wind turbine, it seems that for further wind turbine performance up scaling, employment of superconductors is essential. Superconductors could significantly reduce the size and weight of the wind generators. There are numerous studies dealing with the design of direct-drive synchronous superconducting wind generators with power rates up to $10 \mathrm{MW}^{6-10}$. Terao et al. ${ }^{7}$ present a fully superconducting generator design with $\mathrm{MgB}_{2}$ stator and rotor made of YBCO - 2G HTS racetrack coils. Ohsaki et al. ${ }^{8}$ present a fully superconducting concept based on HTS tapes and Re(BCO) bulks. Stacks of 2G HTS tapes have shown superior magnetic properties ${ }^{11}$ and represent real alternatives to the bulks. Therefore, a conceptual design of a generator (motor) based on magnets made from stacks of tapes will probably be available very soon. Nevertheless, design concepts with a superconducting rotor and a conventional stator are the most common and most likely will be realised first ${ }^{6,9}$. The main reasons for keeping the stator non-superconducting are the AC losses. In a synchronous machine the rotor (bulks or coils) operates in the DC mode, which is in general without any losses. Stator windings must produce AC fields, which mean power losses even in superconductors. It is widely known that AC losses in the stator of a fully superconducting machine are still too high for a feasible design; however, there are methods available to reduce them. One of them is to reduce the number of turns of armature coils and increase the number of poles, as suggested by Zhang et al. ${ }^{12}$

There remain many issues to be solved before superconducting generators and motors can achieve commercial production. Prices of 2 G HTS tapes are still relatively high and the world 2G HTS production capacities are insufficient to supply mass production, e.g. 
conceptual machines presented in ${ }^{6,7}$, which require hundreds of kilometres of $2 \mathrm{G}$ HTS tapes. The other problem is power losses which reduce the efficiency of the machine. Therefore, comprehensive studies of the power losses of the 2G HTS coils are crucial. Numerous outstanding publications deal with AC losses in $2 \mathrm{G}$ HTS tapes ${ }^{13,14}$. Other researchers are focused on $\mathrm{AC}$ losses in racetrack or pancake coils e.g. ${ }^{15-17}$ or in HTS generators as a whole ${ }^{18}$. The most important factor for superconducting generator or motor applications is to know AC losses (stator) and power losses in the rotor. Even though the rotor superconducting coils are in the DC mode, power losses are introduced due to alternating ripple fields. In a synchronous motor or a generator, the magnetic field of the superconducting coil is phase-locked with the stator field, as the coils are under balanced conditions and they experience a DC field from the armature, however in real machines some ripples in the field do occur. Ripple field is present also in generators; however DC field is produced only by other rotor coils. Nonsynchronous disturbances resulting in unbalanced fields in the armature will create power losses in the superconducting rotor coils. Especially in direct-drive wind generators where the disturbances could be much higher as they are caused by non-constant wind speeds and the tower shadow effect. ${ }^{19,20}$ Sources of power losses in wind generators and a rough estimation for particular design was presented by Mijatovic et. al. ${ }^{10}$ Some computer modelling work, analysing of losses caused by ripple fields, was presented in ${ }^{1-3}$. Other papers describe AC losses of HTS tapes or coils measured under certain kinds of external magnetic fields by electrical methods ${ }^{21-23}$, which is possible, though there are always certain field limitations. Calorimetric method seems to be the most straight-forward and effective method of performing HTS coil power loss measurements under various fields. The disadvantages of the method are the very challenging construction of a reliable measurement set-up $\mathrm{p}^{24-27}$ and the limitation of the boiling point of liquid nitrogen which is $\sim 77 \mathrm{~K}$ at standard atmospheric pressure. 


\section{Measurement set-up}

The conceptual design of the measurement set-up has already been presented by Chen et al. 24 The calorimetric measurement set-up consists of two vessels filled with liquid nitrogen (LN). The smaller-inner vessel is placed inside the bigger outer vessel which is insulated by a vacuum chamber. The outer vessel is filled with liquid nitrogen and provides perfect thermal insulation for the inner vessel. Any heat losses in the inner vessel will transform LN into gas which is then measured by a precise gas flow meter. The inner vessel is designed especially for characterization of racetrack coils; however, measuring other kinds of coils or even tapes would be possible after small modifications of the central core assembly (Fig. 1). In the measurement set-up, the

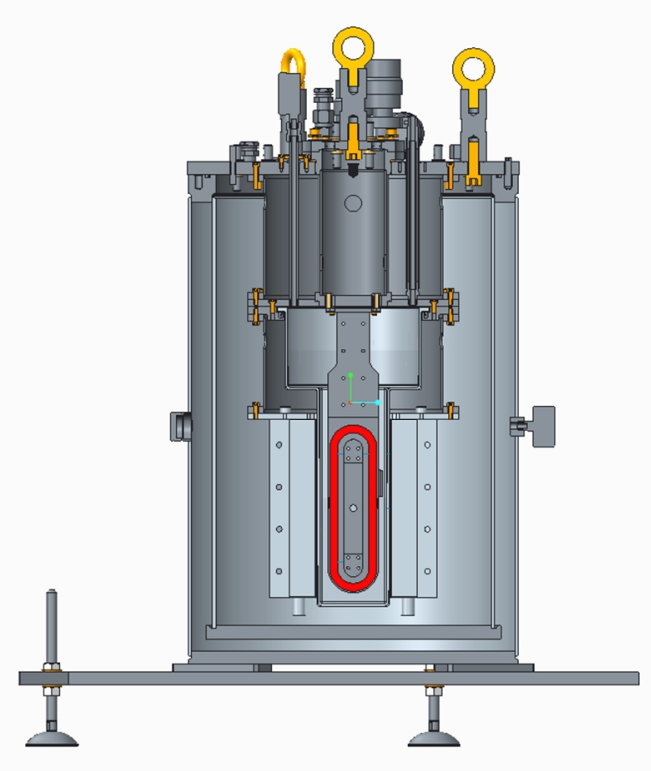

a) 


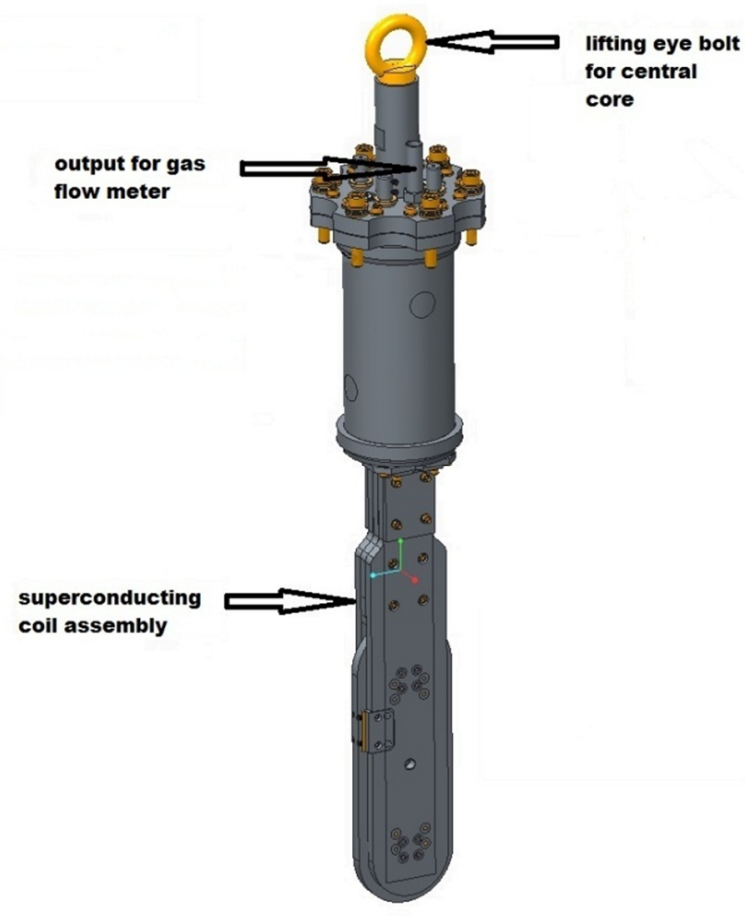

b)

FIG 1: Calorimetric measurement set-up and the Central Core Assembly.

superconducting sample coil is placed in the inner vessel between coils producing external DC or ripple fields. The position of the superconducting sample coil in the relation of the cryostat coils is shown in Fig. 2. The DC coils are able to produce homogenous field up to $250 \mathrm{mT}$. This field is parallel to the axis of the sample coil. These coils could be eventually connected to an AC power supply and produce a ripple field. Due to the limited power of current supply and the relatively high impedance of the coils, the maximum achievable magnetic field is $130 \mathrm{mT}$ peak at $10 \mathrm{~Hz}$. Six other coils produce a ripple field perpendicular to the sample coil axis. They are designed to produce ripples fields of amplitude up to $40 \mathrm{mT}$ and they are connected in 3 phases shifted by $120^{\circ}$. The values were measured by a Hall probe placed on the coil turns. The calibration of the losses was done up to $40 \mathrm{~W}$ using a resistive heater installed inside the inner vessel. The calibration curve was $0.225 \mathrm{SLPM} / \mathrm{W}$ (Standard litres per minute/ Watt) which is within $10 \%$ of the theoretical value of 0.25 $\mathrm{SLPM} / \mathrm{W}^{26}$. The difference is due to nitrogen gas in the flow meter being less than room 
temperature $\left(\sim-20^{\circ} \mathrm{C}\right)$ and also possible micro cracks in the sealing of the inner vessel. For these reasons, a second order polynomial equation was used as the best calibration fit to estimate the loss in watts. Nucleation of nitrogen gas results in variable heat transfer from the superconductor and hence the resolution is limited to $+/-0.5 \mathrm{~W}$. Unfortunately, this is lower than the resolution of electrical methods and it would be insufficient for the characterizing of tapes, where the losses are rather small. Nevertheless, the resolution is satisfactory for coils consisting of long lengths of tapes e.g. $50 \mathrm{~m}$.

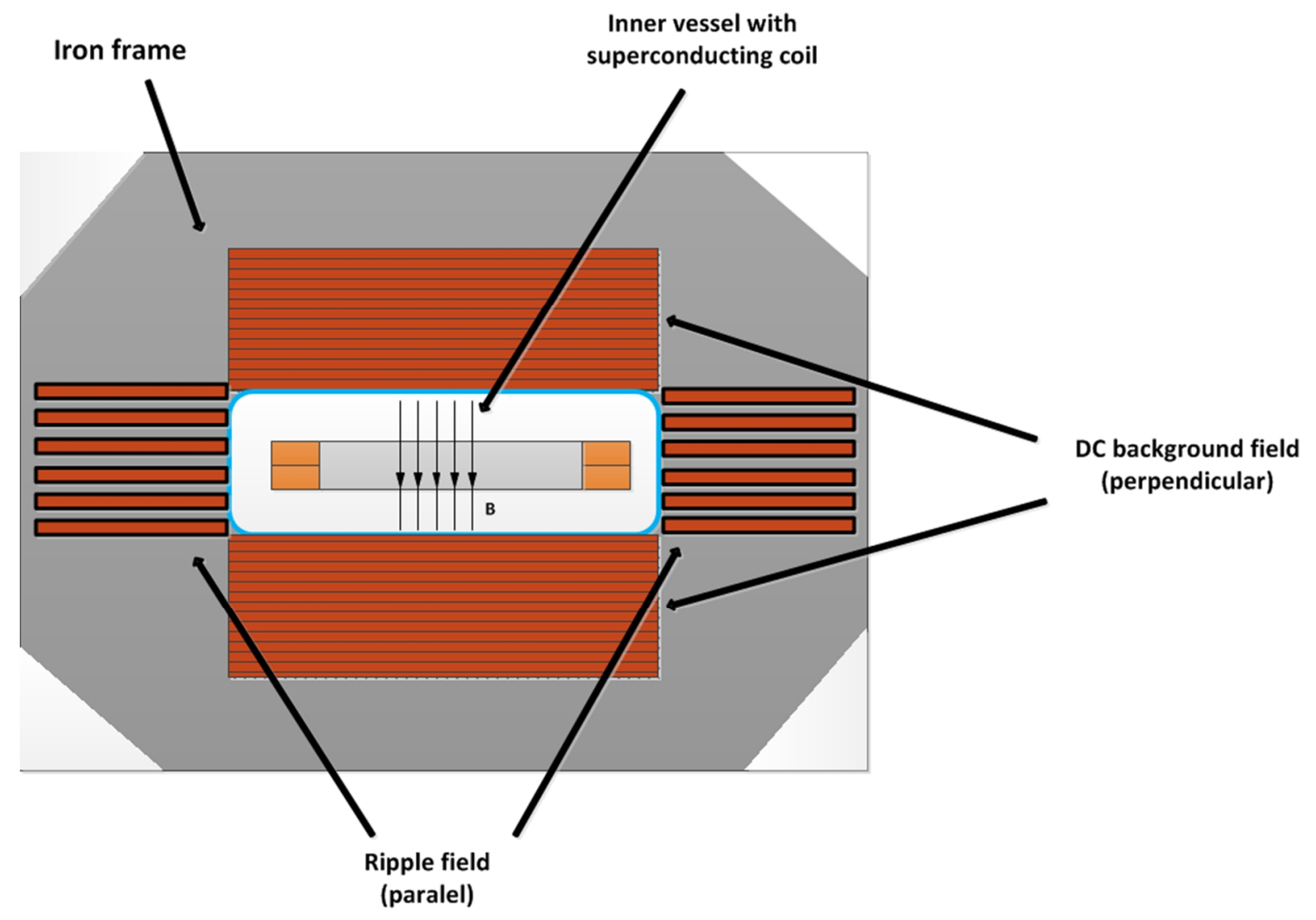

FIG 2: Cross-sectional view of the magnets and the superconducting sample in the cryostat.

\section{Sample}

A superconducting double racetrack coil made from 2G HTS superconducting tape manufactured by SuperPower was used as a sample. The parameters for this sample are listed in Table 1. The critical current of the coil was measured as $36.3 \mathrm{~A}$. 
Table 1: Parameters of the sample 2G HTS racetrack coil.

\begin{tabular}{ll}
\hline & SuperPower 4045 tape $^{28}$ \\
\hline Tape type & 4045 \\
Tape width & $4 \mathrm{~mm}$ \\
Tape thickness & $\sim 0.1 \mathrm{~mm}$ \\
YBCO thickness & $1 \mu \mathrm{m}$ \\
substrate & Non-magnetic $50 \mu \mathrm{m}$ \\
Number of turns & 100 \\
Inner radius & $24 \mathrm{~mm}$ \\
Outer radius & $32 \mathrm{~mm}$ \\
Length & $250 \mathrm{~mm}$ \\
Critical current & $36.3 \mathrm{~A}$ \\
\hline
\end{tabular}

\section{Result and discussion}

In this work, power losses were measured in three different scenarios. The first scenario corresponds to a typical AC loss measurement where the $2 \mathrm{G}$ HTS coil was connected to an AC current source with a perpendicular DC field. The second scenario was the $2 \mathrm{G}$ HTS coil in DC mode, in perpendicular ripple field. In the final scenario the $2 \mathrm{G}$ HTS coil was in the DC mode and subjected to a range of DC background fields (perpendicular to the tape) and ripple fields (parallel to the tape).

\section{A) AC current, DC field}

The main reason for measurements at these settings is to evaluate the reliability of the measurement set-up. The results can be compared with results obtained from the electric method described by Chen et al. ${ }^{17}$ The comparison was done at zero external magnetic field at $20 \mathrm{~Hz}$ AC current in the sample coil. The results are shown in Fig. 3. As loss is almost 
independent of frequency ${ }^{17}$, the plot would be very similar at different frequencies. Results from the calorimetric method at lower currents (under $10 \mathrm{~A}$ ) are below the resolution of the measurement set-up and the points do not represent the real AC loss of the $2 \mathrm{G}$ HTS coil. It might be interesting to note that during the calorimetric measurements, the power losses of the non-superconducting current leads supplying the sample with AC current were up to $90 \%$ of measured power losses within the inner vessel of the cryostat.

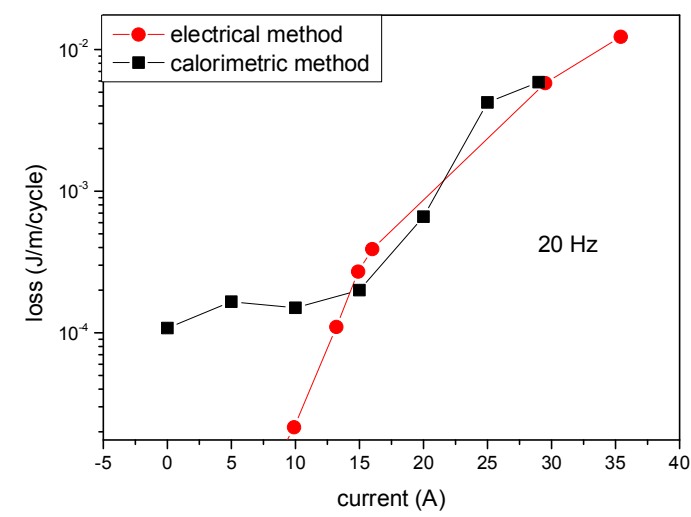

FIG 3: Comparison of results from electrical and calorimetric method.

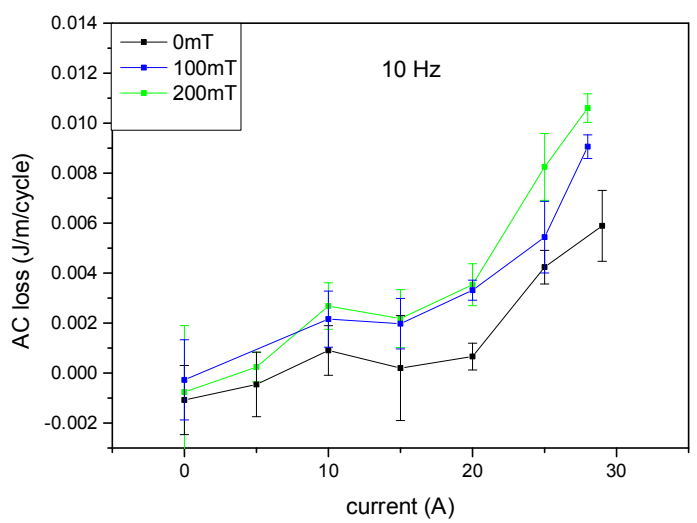

FIG 4: AC losses in different DC magnetic fields.

In Fig. 4, the AC loss measurements at $10 \mathrm{~Hz}$ in various background $\mathrm{DC}$ magnetic fields are presented. As expected, AC losses increase with increasing background DC magnetic field 
due to critical current reduction. It is important to note that this is not a rule for every HTS coil. Coils manufactured from certain anisotropic tapes can increase critical current under certain background magnetic fields ${ }^{29-31}$. Although it is not the case here, an identical coil was characterized under different magnetic fields of different sizes and orientations $i^{29}$ and critical currents were always smaller than compared to the self-field critical current.

B) 2G HTS coil in DC mode + ripple fields

As the $2 \mathrm{G}$ HTS rotor coils of a superconducting generator or motor operate in DC mode, these measurements are the most important results of the paper. The ripple field was produced by the DC background field coils while they were connected in an AC mode as shown in Fig. 5. It was noted before that, if a superconducting coil with a trapped field in persistent mode was exposed to an AC or relatively small ripple field, the current decayed ${ }^{32}$. For very small amplitudes of ripple field changes in the superconductor and losses are limited to the small edge areas of the superconducting tape and the loss is independent of the transport current. However, as the AC fields become larger currents further penetrate the coil, and currents in the coil turns could even reverse. At this point, accordingly some simulations, a discontinuous change of the flux in the sample occurs as the flux moves right across the sample from one side to the other and power losses increase rapidly. This effect could cause serious problems in the operation of superconducting rotating machines. Power losses as an effect of ripple fields in HTS generators were studied by Sivasubramaniam et al. ${ }^{2}$ while $\mathrm{MgB}_{2}$ superconductors was studied by Lahtinen et al. ${ }^{1}$ Power losses introduced by ripple fields are considered to be a serious issue, however; both works were based purely on computer simulations. 
In the experiments, perpendicular ripple fields were applied up to $\sim 200 \mathrm{mT}$. As the coils are surrounded by an iron frame, produced magnetic fields in AC mode were carefully measured by hall probes. Fig's. $6 \mathrm{a}, 6 \mathrm{~b}$ present experimental results at different currents. They represent the same measurements in 2 various scales. The maximum measured current is $35 \mathrm{~A}$, which is very close to the critical current value (36.3 A). Relatively high losses (up to $5.5 \mathrm{~W}$ ) were measured at $35 \mathrm{~A}$, which represents $0.02 \mathrm{~J} / \mathrm{m} /$ cycle. Power losses are reduced with applied DC current in the superconducting coil. At $25 \mathrm{~A}$, power loss of about $1.5 \mathrm{~W}$ was measured under maximum applied field. At $20 \mathrm{~A}$, which represents $55 \%$ of the critical current, all measured losses were under the resolution of the measurement set-up. Again, power loss is expected to be independent on the field frequency and some of the results were re-measured at different frequencies with very similar results. Disadvantages of measurements at higher frequencies are limitations of the AC current source for magnets with relatively high coil impedances. Detectable losses of the measurement set up are $0.001 \mathrm{~J} / \mathrm{m} /$ cycle at $10 \mathrm{~Hz}$ and $0.002 \mathrm{~J} / \mathrm{m} /$ cycle at $5 \mathrm{~Hz}$.

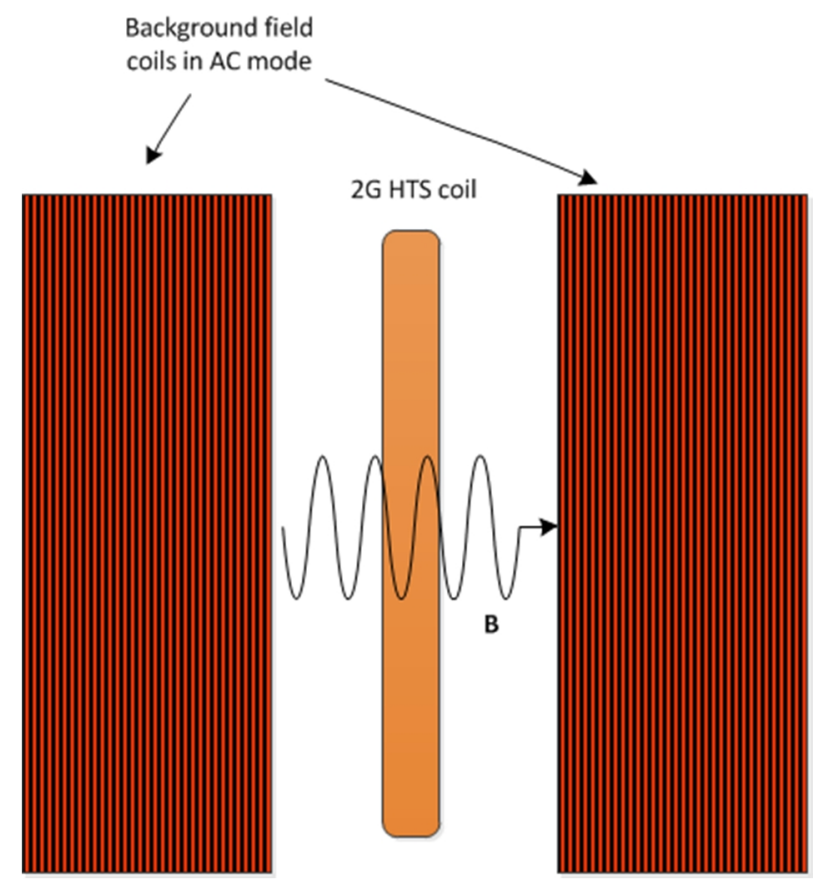

FIG 5: 2G HTS coil in AC field. 


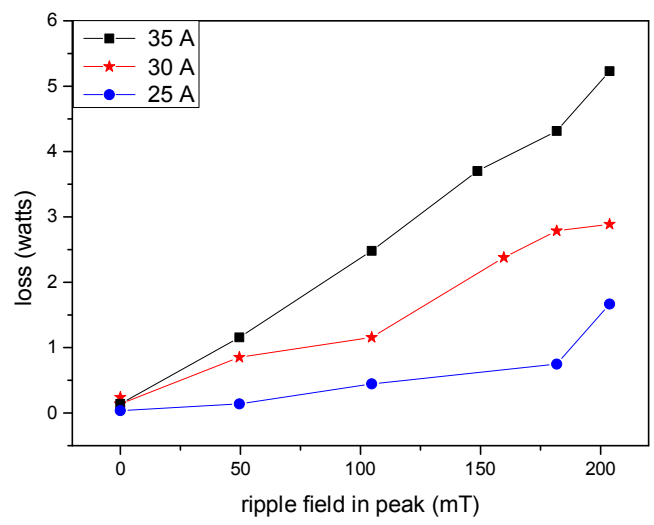

a)

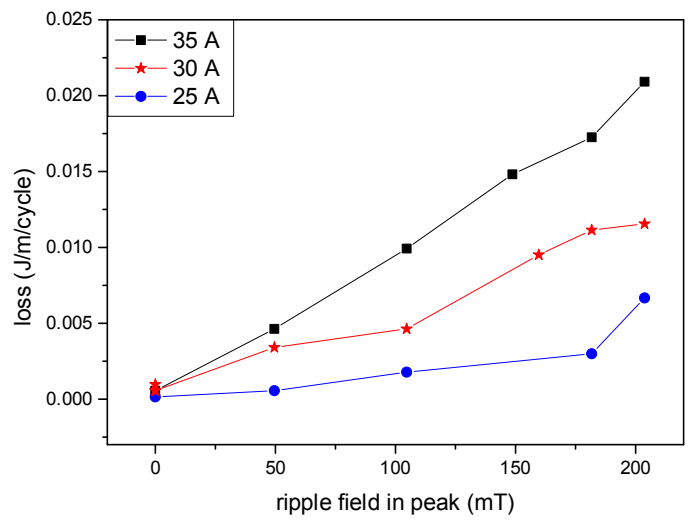

b)

FIG 6: Magnetization losses at $5 \mathrm{~Hz}$ in 2 different scales: a) loss in watts b) loss in $\mathrm{J} / \mathrm{m} / \mathrm{cycle}$.

C) Perpendicular DC background fields and parallel ripple fields

In the last part of the experiment, a ripple field was applied perpendicular to the coil axis, as shown in Fig. 7. Ripple fields of up to $30 \mathrm{mT}$ in peak were produced by 12 ripple field coils (arranged on both sides of the 2G HTS coil). A standard single phase motor invertor was used as a current source for coils. The invertor had 3 phase output and 6 ripple field coils were connected according to Fig. 7. The produced magnetic field was varying as a moving wave. The field was measured with a Hall probe placed on the $2 \mathrm{G}$ HTS coil outer turn. The field was not homogeneous on each turn and it was weakening towards the inner turns. Nevertheless, this is the case in real machines. The ripple frequencies applied during the experiment were from $0.5 \mathrm{~Hz}$ up to $50 \mathrm{~Hz}$. An external DC field up to $250 \mathrm{mT}$ was also 
applied together with the ripple field. Under all these circumstances, no power loss was measured! Any loss higher than $0.5 \mathrm{~W}$ or $2 \times 10^{-4} \mathrm{~J} / \mathrm{m} /$ cycle for the particular coil would be reliably detected. An applied ripple field with $30 \mathrm{mT}$ in peak is probably too low to cause flux movement from one side of the superconductor to the other. In addition, the outermost turn, which is operating far below its critical current, is able to shield the field from the other turns.

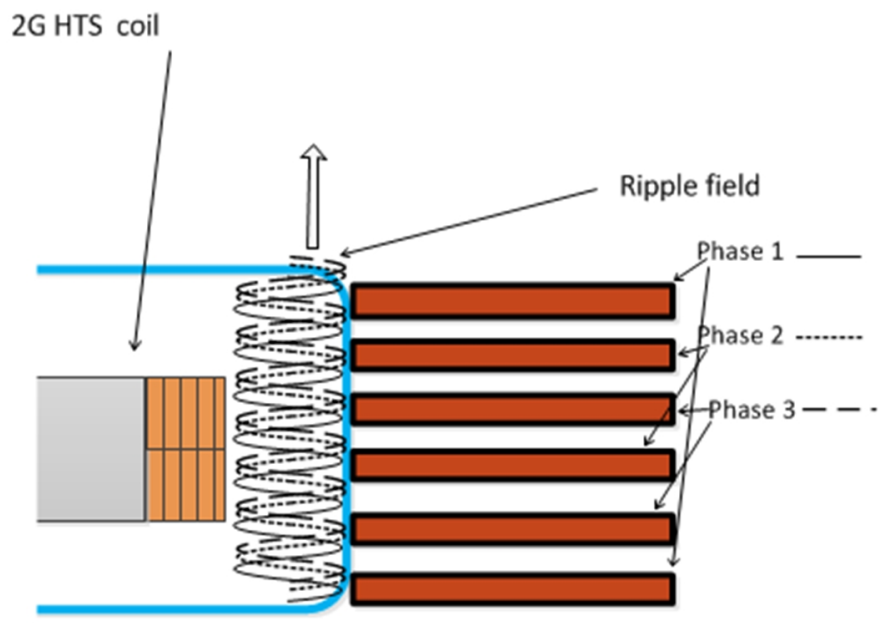

FIG 7: Ripple field coils producing traveling magnetic field.

\section{Conclusions}

Measurements of power losses at various external magnetic fields using the calorimetric method were carried out. The equipment was validated in the first part of experiment. The sensitivity of the calorimetric method is lower than electrical methods, however; several types of measurements cannot be easily carried out using electrical methods. Superconducting coils in rotors of superconducting rotating machines have to withstand ripple fields in both perpendicular and parallel directions. The power losses were measured in parallel direction at different currents. The measurements have shown very small losses at 
currents of about $\sim 50 \%$ of the critical current, up to relatively high losses close to critical the current value. Whereas in the case of ripple fields parallel to the coil axis power losses are relatively high, in the perpendicular direction no losses were detected, even under DC background fields up to $250 \mathrm{mT}$. The experiment has proven that any losses caused by ripple fields in perpendicular direction could be neglected by superconducting generator designs and further work should be focused on losses caused by ripples in parallel direction.

\section{Acknowledgements:}

This work was supported by Grant EPRSC EP/H019294/1. Thank to Prof. Archie Campbell, Prof. Ramesh Bansal and Fred Spaven for their valuable advices on this work.

\section{References}

${ }^{1}$ V. Lahtinen and A. Stenvall, "The Difficulty of Modeling Ripple Field Losses in Superconductors Using the Eddy Current Model”, IEEE Trans.Appl. Supercond. 23, 3 (2013).

${ }^{2}$ K. Sivasubramaniam, X. Huang, D. Ryan, K. Weeber, J. W. Bray, E. T. Laskaris, L. Tomaino, J. M. Fogarty, and S. Ashworth, "AC Losses in a High Temperature Superconducting Generator”, IEEE Trans.Appl. Supercond 15, 2 (2005).

${ }^{3}$ F. Grilli, E. Pardo, A. Stenvall, D. N. Nguyen, W. Yuan, and F. Gömöry," Computation of Losses in HTS Under the Action of Varying Magnetic Fields and Currents", IEEE Trans.Appl. Supercond., in press.

${ }^{4}$ E. Pardo, J. Kováč, and J. Souc," Power Loss in ReBCO Racetrack Coils Under AC Applied Magnetic Field and DC Current”. IEEE Trans.Appl. Supercond. 23, 3 (2013).

${ }^{5}$ D. Robb, "The gearbox challenge - the role of bearings in gearbox failure", Windpower Monthly magazine, pp 53-60, November 2005. 
${ }^{6}$ A. B. Abrahamsen, N. Mijatovic, E. Seiler, T. Zirngibl, C. Træholt, P. B. Nørg ${ }^{\circ}$ ard, N. F. Pedersen, N. H. Andersen and J. Østerg ${ }^{\circ}$ ard, "Superconducting wind turbine generators", Supercond. Sci. Technol. 23, 034019 (8pp) (2010).

${ }^{7}$ Y. Terao, M. Sekino and H. Ohsaki, "Comparison of Conventional and Superconducting Generator Concepts for Offshore Wind Turbines", IEEE Trans.Appl. Supercond. 23, 3 (2013).

${ }^{8}$ H. Ohsaki, M. Sekino, T. Suzuki, and Y. Terao, ” Design Study of Wind Turbine Generators using Superconducting Coils and Bulks", Clean Electrical Power, 2009 International Conference on, pp 479 - 484 (2009).

${ }^{9}$ O. Keysan and M. A. Mueller, "Superconducting generators for renewable energy applications", IEEE Trans.Appl. Supercond. 21, 5 (2011).

${ }^{10}$ N. Mijatovic, A. B. Abrahamsen, C. Træholt, E. Seiler, M. Henriksen, V. M. RodriguezZermeno, N. F. Pedersen," Superconducting generators for wind turbines: design considerations", Journal of Physics: Conference Series 234, 032038, (2010).

${ }^{11}$ A. Patel, S C Hopkins and B A Glowacki, "Trapped fields up to $2 \mathrm{~T}$ in a $12 \mathrm{~mm}$ square stack of commercial superconducting tape using pulsed field magnetization" ,Supercond. Sci. Technol.26 032001 (7pp) (2013).

${ }^{12}$ M. Zhang, M. Chudy, W. Wang, Y. Chen, Z. Huang, Z. Zhong, W. Yuan, J. Kvitkovic, S. V. Pamidi, and T. A. Coombs, "AC Loss Estimation of HTS Armature Windings for Electric Machines", IEEE Trans.Appl. Supercond. 23, 3 (2013).

${ }^{13}$ R. Pei, A, Velichko, M. Majoros, Y. Jiang, R. Viznichenko, Z. Hong, R. Marchant, A. M. Campbell and T. A. Coombs, "Ic and AC loss of 2G YBCO tape measurement for designing and fabrication of an HTS motor" ", IEEE Trans.Appl. Supercond 18, 2, 1236-1239 (2008).

${ }^{14}$ S. H. Rupp, A. D. Caplin, M. P. Staines, "Magnetisation ac-loss measurements on YBa2Cu3O7 tapes with weakly-ferromagnetic NiW substrates", Journal of Physics: Conference Series 97,012078, (2008). 
${ }^{15}$ J. H. Claassen," An approximate method to estimate AC loss in tape-wound superconducting coils” Appl. Phys. Lett. 88, 122512 (2006).

${ }^{16}$ J. Souc, E. Pardo, M. Vojenciak, and F. Gomory. "Theoretical and experimental study of ac loss in high temperature superconductor single pancake coils", Supercond. Sci. Technol., 22,015006 (2009).

${ }^{17}$ Y. Chen, M. Zhang, M. Chudy, K. Matsuda, T. Coombs, "Complex Study of Transport AC Loss in Various 2G HTS Racetrack Coils”, Physica C, 489, 15 , pp 1-7 (2013).

${ }^{18}$ L. Quéval and H. Ohsaki," AC Losses of a Grid-Connected Superconducting Wind Turbine Generator”, IEEE Trans.Appl. Supercond. 23, 3 (2013).

${ }^{19}$ S. Das, N. Karnik, and S. Santoso, "Time-Domain Modelling of Tower Shadow and Wind Shear in Wind Turbines", ISRN Renewable Energy Volume 2011, Article ID 890582, 11 pages, doi:10.5402/2011/890582.

${ }^{20}$ Dale S.L. Dolan, P.W. Lehn, "Simulation Model of Wind Turbine 3p Torque Oscillations due to Wind Shear and Tower Shadow", IEEE Power Systems Conference and Exposition, 2006. PSCE '06. 2006 IEEE PES ,pages 2050 - 2057 10.1109/PSCE.2006.296240.

${ }^{21}$ E. Pardo, J. Kováč, and J. Šouc,” Magnetization Loss in HTS Stacked Tapes by Various Directional External Magnetic Fields”, IEEE Trans.Appl. Supercond. 23, 3 (2013)

${ }^{22}$ J. Šouc, F. Gömöry, and M. Vojenèiak, "Calibration free method for measurementof the ac magnetization loss," Supercond. Sci. Technol. 18, 592 (2005).

${ }^{23}$ Y. Chen, M. Zhang, M. Chudy, W. Wang, Z. Zhong, Z. Huang, and T. Coombs, "Theoretical and experimental magnetization loss comparison between IBAD coils and RABiTS coils“, IEEE transaction on applied superconductivity, VOL. 23. ISSN 1051-8223 (2013).

${ }^{24}$ Y. Chen, W. Yuan, M. Zhang, and T. A. Coombs, "The Experiment to Evaluate the AC Loss of 2 G HTS Windings in the Application of Rotating Electric Machines", IEEE Trans.Appl. Supercond. 22, 3 (2012). 
${ }^{25}$ N. Magnusson and S. Hörnfeldt," Calorimetric apparatus for alternating current loss measurements on high-temperature superconductors", Rev. Sci. Instrum. 69, 3320 (1998).

${ }^{26}$ J. Ekin," Experimental Techniques: Cryostat Design, Material Properties and Superconductor Critical-Current Testing, U.S.A.: Oxford University Press, ISBN: 9780198570547 (2006).

${ }^{27}$ Jae-Ho Kim, C. H. Kim, G.Iyyani, J. Kvitkovic, and S. Pamidi, "Transport AC Loss Measurements in Superconducting Coils IEEE Trans.Appl. Supercond.21, 3, ( 2011)

${ }^{28}$ http://www.superpower-inc.com/content/products-services

${ }^{29}$ M. Chudy, Y. Chen, M. Zhang and T. A. Coombs, " Anisotropy of 2G HTS racetrack coils in external magnetic fields", Supercond. Sci. Technol. 26075012 (7pp) (2013)

30 J. Pitel, P. Kováč, “Influence of external magnetic fields on critical currents of solenoids wound with anisotropic HTS tapes - Theoretical analysis”, Supercond. Sci. Technol. 10 (1), pp. 7-16 (1997).

${ }^{31}$ J. Pitel, P. Kováč, Compensation of the radial magnetic field component of solenoids wound with anisotropic Bi(2223)Ag tape , 1997, Supercond. Sci. Technol. 10 (11), pp. 847-852 (1997).

${ }^{32}$ S. Jeong, J. V. Minervini, J. R. Hale, Y. J. Chen "Persistent Current Decay of a Superconducting Coil in an AC Field" Advances in Cryogenic Engineering Volume 39, pp 17-24 (1994). 